\title{
Studies Using DNA Markers in Fragaria × ananassa: Genetic Analysis, Genome Structure, and Cultivar Identification
}

\author{
Miyuki Kunihisa
}

National Institute of Vegetable and Tea Science, Kannondai 3-1-1, Tsukuba 305-8666, Japan

\begin{abstract}
The cultivated strawberry, Fragaria $\times$ ananassa $(2 n=8 x=56)$, is an economically important crop in many regions of the world, and many breeding programs are competing to produce new, high-value cultivars. Despite this level of interest, marker-assisted selection of strawberry based on QTL analysis has lagged behind that of diploid crops because of its complex polyploidy and unclear genomic construction. During the past decade, great progress in the development of DNA markers has begun to overcome these difficulties, and the study of inheritance, mapping, and phylogeny is proceeding rapidly. Meanwhile, strawberry breeders have become much more aware of their rights with respect to the cultivars they have developed, as the volumes of harvested fruits that are transported globally have increased. To address the need to identify illegally grown strawberry fruits, genomics researchers have been required to develop simple and reproducible techniques for cultivar identification. This review summarizes the recent development of DNA marker studies in $F$. × ananassa, with a focus on the genome-specific markers we have developed.
\end{abstract}

Key Words: disomic, DNA marker, genome-specific, octoploid, validation.

\section{Introduction}

In plants, polyploidy is especially prevalent; $30-40 \%$ of flowering plants are estimated to be polyploid (Stebbins, 1971). Nevertheless, the genetic study of polyploids is considerably delayed compared to that of diploids because of their often complicated or unclear genetic behavior. Many economically important crops are polyploid, including strawberry (the focus of this review), wheat, sugarcane, potato, sweet potato, rose, chrysanthemum, and others; for this reason, progress in the genetic study of polyploids would be highly desirable.

Polyploids are generally classified as either auto- or allopolyploid. Autopolyploids are believed to be formed via chromosome doubling of a single species. Autopolyploids show polysomic inheritance, which assists them in maintaining heterozygosity. Heterozygosis decreases the frequency of exhibition of recessive characteristics and preserves desirable phenotypes. Most autopolyploids are allogamous (cross-pollinated), which also helps to maintain heterozygosity (MacKey, 1970; Stebbins, 1971). In contrast, allopolyploids are consid-

Received; February 1, 2011. Accepted; April 12, 2011.

E-mail: miyuky@affrc.go.jp. ered to have arisen from interspecies crosses followed by chromosome doubling. Allopolyploids consist of multiple genomes, each of which exhibits disomic inheritance, which accelerates the homozygosis of mutated alleles and the expression of new phenotypes. This mechanism is advantageous for exposure to natural selection and rapid evolution, enabling the plant to adapt to various environments; therefore, autopolyploids are apt to develop into amphidiploids through the differentiation of homologous chromosomes by mutation or rearrangement (e.g., AAAA to AAA'A'). Many angiosperms commonly considered as diploid are thought to be highly amphidiploidized polyploids from the phylogenetic viewpoint (Da Silva, 1996; MacKey, 1987).

The most well-known and well-understood polyploid crop is wheat (Triticum aestivum L.), which is an allohexaploid consisting of A, B, and D genomes, the donors of which are Triticum urartu, Aegilops speltoides, and Aegilops tauschii, respectively. The research of wheat is exceptionally advanced based on firm genetic theory and clearly identified genome origins. On the other hand, most other polyploid crops have been difficult to research owing to their complex or unclear manners of inheritance. Some polyploids may possess both disomic and polysomic genomes (e.g., AABBBB); others may exhibit ill-defined inheritance as the genome 
is in the process of evolving from an autopolyploid to an amphidiploid.

In 2008, the world production of strawberries exceeded 4 million tonnes (FAOSTAT Agricultural Data; http://faostat.fao.org/site/339/default.aspx), and is increasing every year. In Japan, strawberries had the third-highest level of output among commercial crops (after rice and tomatoes) in 2009. As the economic importance of strawberries is increasing, more advanced theory and techniques are required for rapid breeding of cultivars satisfying the various needs of the market. Therefore, continuous genomic study of the cultivated strawberry is needed, with resolution of its genome structure being a primary goal.

The cultivated strawberry (Fragaria $\times$ ananassa) is an octoploid, but its genome constitution has yet not to be resolved. Two main hypotheses have been proposed: (1) allo-autopolyploidy (AAA'A'BBBB), based on observation of meiotic pairing (Senanayake and Bringhurst, 1967) and (2) allopolyploidy (AAA'A'BBB'B'), based on isozyme segregation patterns (Bringhurst, 1990). Both hypotheses indicate that $F \times$ ananassa is a complex polyploid with multiple independent genomes, at least two of which are disomic; however, data directly indicating disomic inheritance had rarely been observed, possibly due to masking by homoeologous genes, and the development of strawberry breeding based on solid theory has been shackled by its still-unexplained genome. The octoploid Fragaria species are believed to have been formed following chromosome doubling and interspecies crosses of several diploid wild strawberries (Senanayake and Bringhurst, 1967); however, it has not been revealed which diploids have participated in the constitution of this octoploid. The identification of genome donors would contribute to understanding the complex genome constitution of $F$. $\times$ ananassa.

Meanwhile, new strawberry cultivars appear in the marketplace year after year, as consumers demand highvalue fruits. In the 1990s, only two cultivars, 'Nyoho' and 'Toyonoka', occupied most of the market share in Japan. Recently, we are able to obtain more than 10 cultivars even in a local supermarket; these included 'Tochiotome', 'Sachinoka', 'Akihime', 'Benihoppe', 'Amaou' (Cultivar name: 'Fukuoka S6'), 'Sagahonoka', 'Hinoshizuku' (Cultivar name: 'Kumaken I 548'), and others. Many prefectures have bred their own original cultivars to boost their regional agriculture and have registered these cultivars to protect breeders' rights. Illegal propagation is a particular concern with vegetatively propagated crops. The interest in breeders' rights is increasing worldwide. The membership of the International Union for the Protection of New Varieties of Plants (UPOV), established in 1961, is now at 3.5 times the level in 1990. Therefore, rapid and reliable DNA techniques to identify cultivars have been requested and developed.

Several types of DNA markers were developed for
Fragaria species with the aim of measuring genetic relationships (Degani et al., 2001; Harrison et al., 1997), analyzing genetic linkage (Haymes et al., 1997), and identifying cultivars (Arnau et al., 2003; Congiu et al., 2000; Tyrka et al., 2002). These DNA markers include restriction fragment length polymorphism (RFLP), random amplified polymorphic DNA (RAPD), amplified fragment length polymorphism (AFLP), and inter simple sequence repeat (ISSR) markers. Subsequently, simple sequence repeat (SSR) (Ashley et al., 2003; Lewers et al., 2005; Shimomura and Hirashima, 2006) and cleaved amplified polymorphic sequence (CAPS) markers (Kunihisa et al., 2003, 2005a) were introduced. The reported CAPS markers were characterized by their genome-specificity. In most cases, they could selectively amplify single loci in octoploid strawberry, while other kinds of markers simultaneously amplified homoeologous loci; therefore, genome-specific markers could be practically treated as co-dominant, and provided information we could not obtain by other kinds of markers. On the other hand, the number of sequences of $F \times$ ananassa stored in the DNA Data Bank of Japan (DDBJ; www.ddbj.nig.ac.jp/index-e.html) was only 67 in 2001 but had increased to over 1600 in 2010 . Moreover, 6200 expressed sequence tags (including 670 with SSR) have been released in the Genome Database of Rosaceae (www.rosaceae.org). The riddles of the strawberry genome mentioned above are being steadily answered, assisted by the progress of DNA markers and genomic decoding. This review summarizes recent genomic studies, including fingerprinting of cultivars, in $F$. $\times$ ananassa, with a focus on the genome-specific DNA markers we have studied.

\section{Genetic analyses of $F$. $\times$ ananassa}

\section{1) Development of genome-specific DNA markers}

The first reports of molecular markers for $F . \times$ ananassa introduced isozymes as a means to classify or identify cultivars; in those studies, three different enzymes were used (Bringhurst et al., 1978, 1979). Subsequently, authors proposed a diploidized model of the octoploid genome based on the observation of the inheritance of phosphoglucose isomerase (PGI); one isozyme among the four PGIs in cultivated strawberry segregated in a $3: 1$ ratio, which could be construed as $1: 2: 1$ if the thickness of bands in the electrophoresis gel was considered (Arulsekar et al., 1981). This had been the only report of disomic segregation in cultivated strawberry. Though $3: 1$ or $1: 1$ segregations of phenotypic traits have been frequently reported in breeding studies of strawberry (Monma et al., 1990; Sugimoto et al., 2005), they indicate that a trait is controlled by a single dominant gene, not necessarily that its inheritance is disomic. The first type of DNA marker, RFLP, was utilized for classification of Fragaria species other than $F$. $\times$ ananassa (Harrison et al., 1997). Isozymes and RFLP markers are useful due to their co- 
dominance, however, they are onerous to handle. Soon, PCR-based markers such as RAPD, AFLP, and ISSR markers were adopted because of their ease of use and high ability to detect polymorphisms. Haymes et al. (1997) worked to develop DNA markers linked to a phenotype, Phytophthora fragariae resistance, and presented a primitive linkage map of cultivated strawberry developed by using RAPD markers. Degani et al. $(1998,2001)$ applied RAPD and AFLP markers to identify strawberry cultivars, and compared genetic relationships to pedigree data. Arnau et al. (2003) also studied cultivar identification and genetic distance using ISSR markers. However, RAPD, AFLP, and ISSR markers are all dominant, which are less informative than co-dominant markers. Moreover, the amplicons obtained with these markers are not very reproducible across different instruments or researchers, owing to competition between the unknown number of loci targeted by general primers (Halldén et al., 1996).

To overcome these limitations, efforts to develop CAPS markers as the first co-dominant PCR-based markers were begun in octoploid strawberry (Kunihisa et al., 2003). Primer pairs were designed based on 34 gene sequences (including introns) of Fragaria spp., which were available from the DDBJ. An amplified product from a single gene of $F$. $\times$ ananassa was expected to contain eight homoeologous sequences. The amplicons were subcloned into T-vector, and the sequences of multiple clones were obtained. Polymorphisms observed among homoeologous sequences could be explained as either "genome-specific sequences", common to the alleles from a particular genome, or "allele-specific sequences", detectable as DNA markers; however, it was difficult to distinguish between these alternatives. A comparison of many sequences from different cultivars revealed some polymorphisms among cultivars (allele-specific sequences), and CAPS markers could be developed (Fig. 1, panels designated "a"). Because they detected specific genes, much higher reproducibility was acquired with them than with the dominant markers mentioned above; however, the signals of the polymorphic bands were relatively weak and sometimes invisible, because eight homoeologous sequences still competed against each other for amplification. Moreover, the zygosity of detected polymorphisms could not be determined because of indistinguishable amplicons from homoeologous loci; therefore, CAPS markers needed to be treated as dominant in spite of their co-dominance.

To solve these problems, Kunihisa et al. (2005a, 2009a) attempted to develop "genome-specific markers" that would detect single loci (i.e., loci from isogenomes) as a means of obtaining stable and genuine co-dominant markers; to do this, they searched for genome-specific sequences. A total of 20-25 varied sequences derived from five cultivars were classified for each gene using the unweighted pair group method with the arithmetic
A

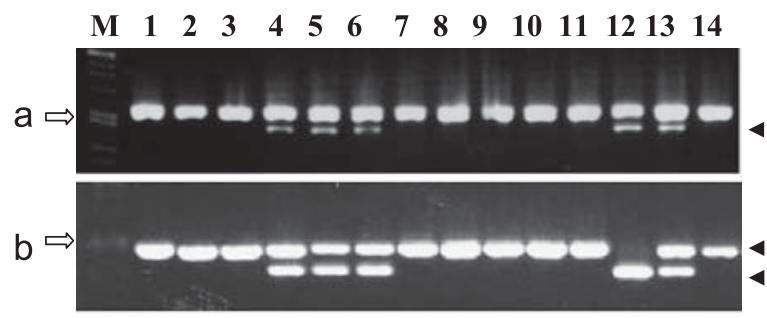

B

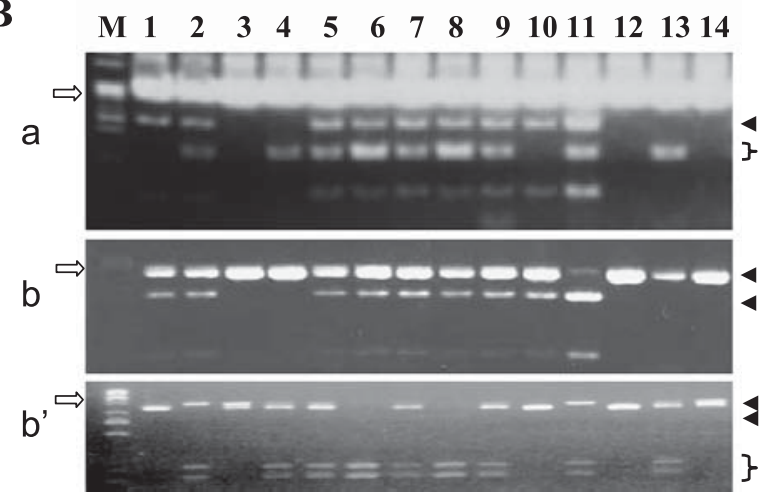

Fig. 1. Examples of original and cluster-specific CAPS markers. Within each panel, "a" shows analysis with the original marker; "b" and "b" show analysis with cluster-specific markers. A: CHI-Pvu II markers. Example of a situation in which a single polymorphism could be detected by the original marker (a) but was clearer to score when the cluster-specific marker was used (b). B: PYD-Hae III markers. Example of a situation in which two polymorphisms could be detected by the original marker (a). Analysis by cluster-specific markers ( $b$ and b') indicated that these polymorphisms belonged to separate clusters. Lanes 1 to 14, 'Toyonoka', 'Nyoho', 'Tochiotome', 'Akihime', 'Sachinoka', 'Aiberry', 'Redpearl', 'Nohime', 'Sanchigo', 'Pistro', 'Aistro', 'Benihoppe', 'Kekiwase', and 'Kurume IH-1 go', respectively. M, size marker (HindIII/HincII fragments). White arrows indicate 530-bp marker; black arrows or brackets indicate polymorphic bands.

(UPGMA) mean. Sequences could generally be divided into three or four clusters independent of the cultivar (Fig. 2), and these clusters were considered to reflect genome construction. Using primers designed to anneal to the cluster-specific sequences, 25 CAPS markers were converted into cluster-specific ones (Fig. 1, panels designated "b"). Almost all of the cluster-specific markers segregated in a $1: 2: 1$ ratio in the offspring of an $a b \times a b$ cross, or $1: 1: 1: 1$ in an $a b \times b c$ cross. If the markers had been inherited in a polysomic manner, the $\mathrm{ab} \times \mathrm{ab}$ cross (actually aabb $\times$ aabb, or some other polysomic combination) would have generated varied types of heterozygous progenies, such as abbb, aabb, and aaab, and these ratios of allele types would be reflected in the variation in band intensity (Da Silva and Sobral, 1996; Martinez-Zapater and Oliver, 1984; Truong et al., 2005). However, the detected signal intensity in all heterozygotes was uniform $(a: b=1: 1)$ (Kunihisa, 2008). In any segregation analyses of these markers using five cross populations, genotypes 

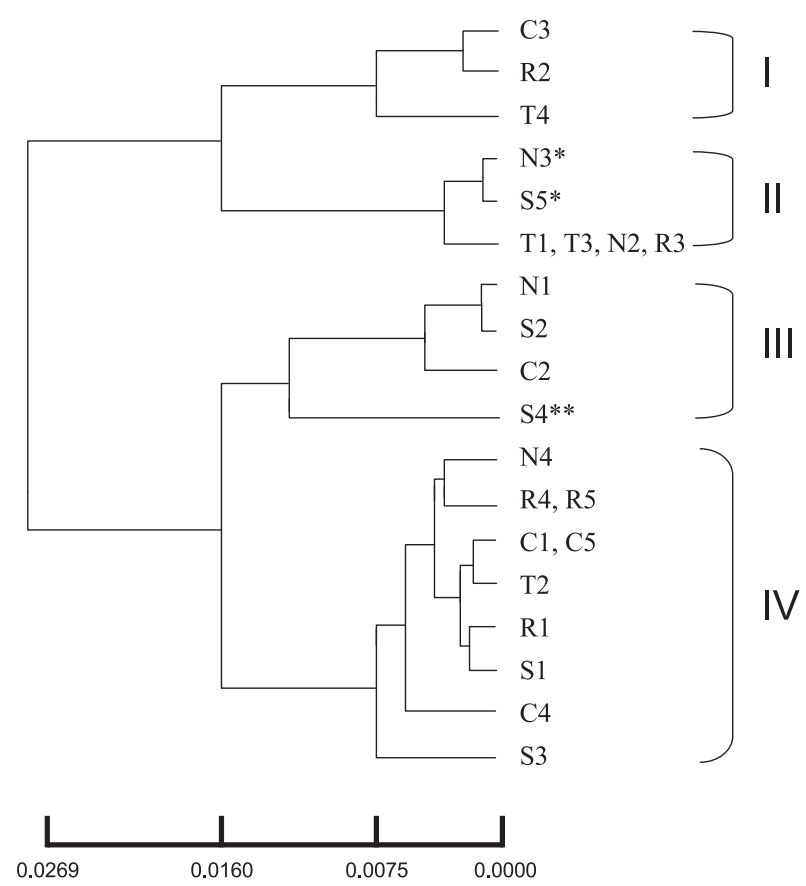

Fig. 2. Classification of various sequences of the Pyruvate decarboxylase $(P Y D)$ gene from five cultivars by their sequences (the base pair range of sequences is $545-573 \mathrm{bp}$ ). S1-S5, sequences from 'Sachinoka'; T1-T4, sequences from 'Tochiotome'; N1-N4, sequences from 'Nyoho'; R1-R5, sequences from 'Redpearl'; $\mathrm{C} 1-\mathrm{C} 5$, sequences from 'Cesena'. This classification was assessed by the UPGMA method. I-IV indicate division of the sequences into classes. Asterisks indicate the sequences that produced the polymorphic signal ( $374 \mathrm{bp}$ ), and double asterisk indicates the sequence that generated the other polymorphic signals ( $261 \mathrm{bp}$ and $236 \mathrm{bp}$ ) in CAPS analysis. The remaining sequences all gave the same banding pattern in the analysis.

indicating polysomic inheritance were never detected. Considering these results, they concluded that the clusterspecific markers successfully detected single disomic loci; that is, they were genome-specific. With these markers, the disomic behavior of many loci of cultivated strawberry could be confirmed. Additionally, these developed markers could be treated as co-dominant in every analysis. Cluster analysis of sequence data was useful for the distinguishment between homoeologous loci and for the better understanding of the genome construction of $F$. $\times$ ananassa.

Another type of co-dominant marker, SSR, was developed in wild strawberry (Ashley et al., 2003) and then in $F$. $\times$ ananassa (Lewers et al., 2005; Shimomura and Hirashima, 2006) (Fig. 3). SSRs have been extensively developed and have become a mainstay of genomic studies (Bassil et al., 2006; Davis et al., 2006; Rousseau-Gueutin et al., 2008; Sargent et al., 2009). Because SSR primers developed in octoploid strawberry usually amplify more than one locus, SSR markers have the same problems as the original CAPS markers owing to competing and indistinguishable homoeologous loci; the instability of signals and the treatment as dominant

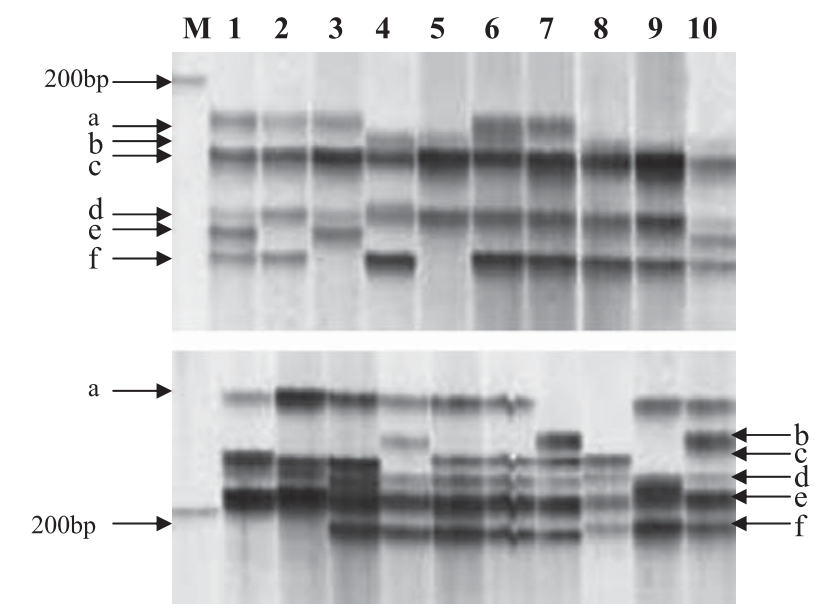

Fig. 3. Examples of SSR markers (Shimomura and Hirashima, 2006). SSR profiles produced by amplification with two sets of primers. DNA was separated by denaturing PAGE ( $5 \%$ acrylamide, $7 \mathrm{M}$ urea). M, size marker (100-bp DNA ladder). Lanes 1 to 10 , 'Toyonoka', 'Sachinoka', 'Fukuoka S6', 'Nyoho', 'Tochiotome', 'Asuka Ruby', 'Redpearl', 'Sagahonoka', 'Akihime', and 'Aiberry', respectively. Arrows labeled "a" to "f" indicate bands representing alleles found in these cultivars.

markers. However, SSRs specific to a diploid genome are occasionally obtained by chance; for example, Ashley et al. (2003) reported that some SSR markers were unintentionally specific to disomic loci in $F$. virginiana. The accumulation of such genome-specific markers will facilitate various genetic studies of $F$. ananassa, such as the integration of genetic maps, genetic pedigree diagnosis of breeding lines, and so on.

The use of genome-specific markers helps us to detect or trace a specific genome across cultivars or species. For example, aneuploid strawberry $(2 n=8 x+2)$, generated from a cross of $F$. vesca and $F$. ananassa, was confirmed to be the result of a homozygous unreduced pollen grain produced by second-division restitution; this was determined through the observation that CAPS markers which were heterozygous in the parental $F . \times$ ananassa were homozygous in the aneuploids (Yanagi et al., 2010). Although there is great deal of complexity in the study of polyploids, they possess inestimable genetic capacity. The manipulation of ploidy is one of the interesting strategies available to assess their capacity. Analyses to determine which chromosome has been lost (or duplicated) in artificially constructed aneuploids are indispensable for more advanced study. The arrangement of markers specific to each of the 28 chromosomes ( $1 \mathrm{~A}$ to $7 \mathrm{~B}^{\prime}$ ) will help us to detect and identify each chromosome included in aneuploids or interspecific hybrids.

\section{2) Composition of the octoploid genome of $F$. $\times$ ananassa}

Federova (1946) suggested AABBBBCC as the genome composition of the octoploid strawberry on the basis of cytological observations. This was later modified to $\mathrm{AAA}^{\prime} \mathrm{A}^{\prime} \mathrm{BBBB}$, due to occasional meiotic pairing 
of the $\mathrm{A}$ and $\mathrm{C}$ genomes of interspecies hybrids (Senanayake and Bringhurst, 1967). The observation of multivalent chromosomes during meiosis (Mok and Evans, 1971) supported this hypothesis. On the other hand, only bivalent chromosomes were observed in many studies (Byrne and Jelenkovic, 1976; Ibrahim et al., 1981; Ichijima, 1926; Longley, 1926; Powers, 1944). However, the presence of bivalent chromosomes does not always indicate disomic behavior. Bivalent pairing is preferred even in cases of polysomic inheritance because of genes regulating meiotic pairing, such as $P h$ in wheat (Wall et al., 1971). For example, Da Silva et al. (1993, 1996) showed that wild sugarcane displays polysomic inheritance despite presenting bivalent pairing at meiosis. Genetic analyses, such as the observation of segregation ratios indicating disomic inheritance (e.g., $1: 2: 1$ for a cross of $a b \times a b$ or $1: 1: 1: 1$ for a cross of $a b \times b c)$, are better indicators of the type of meiotic behavior. Arulsekar et al. (1981) studied the PGI isozymes in $F$. ananassa and assumed that they were encoded by genes at four homoeologous loci. Based on these reports, the formula was refined to AAA'A'BBB'B' (Bringhurst, 1990). However, Lerceteau-Köhler et al. (2003) advocated the genome formula AAA'A'BBBB, based on the low frequency of mapped DNA markers in the repulsion phase. Kunihisa et al. (2005a, 2009a) also examined the genomic construction of $F$. $\times$ ananassa through the study of genome-specific markers, and concluded that it was highly diploidized (i.e., genome formula $\mathrm{AAA}^{\prime} \mathrm{A}^{\prime} \mathrm{BBB} \mathrm{B}^{\prime}$ ), based on the following three results. First, over $75 \%$ of the identified polymorphisms could be detected as diploid genome-specific markers. The remaining $25 \%$ were thought not to appear as genome-specific because sufficiently specific primers could not be designed owing to highly preserved sequences among genomes. This indicated that most of the loci of $F . \times$ ananassa were disomic. Second, genotypes indicating polysomic inheritance were never detected in any segregation analyses of 25 markers using five cross populations. Last, three independent disomic genome-specific markers, derived from different genome clusters for a single gene (that encoding ascorbate peroxidase), were obtained. These three disomic loci were assumed to be homoeologous; if so, then the remaining (fourth) locus must also be disomic. Based on these findings, the authors have concluded that $F$. $\times$ ananassa is amphidiploid, or close to it.

Rousseau-Gueutin et al. (2008) advanced the available genetic map using SSR markers, and they showed that almost all of the linkage groups consisted of markers with a $1: 1$ ratio of coupling- to repulsion-phase linkage; therefore, they also concluded that meiotic behavior is mainly disomic in $F$. $\times$ ananassa. No polysomic segregation was observed in recent high-quality mapping studies (Sargent et al., 2009); therefore, the genome formula AAA'A'BBB'B' is generally accepted at present. However, the possibility of polysomic pairing at a low frequency remains, as the cultivated strawberry might be still in an ongoing evolutional process toward becoming amphidiploid. Rousseau-Gueutin et al. (2008) were concerned about a few linkage groups that did not contain markers in the repulsion phase, and suggested the possibility of residual levels of polysomic inheritance. Assessment of the frequency of genotypes indicating polysomic pairing (e.g., genotypes other than $a b$ in the progeny of an aa $\times$ bb cross), generated using a very large population, might answer this question.

\section{3) Genetic mapping and markers}

The first genetic markers and linkage map in $F . \times$ ananassa were developed using RAPD analyses (Haymes et al., 1997). Seven RAPD markers linked to the Phytophthora fragariae resistance (Rpf) gene were identified through bulk segregant analyses and formed a single linkage group. Sugimoto et al. (2005) identified two RAPD markers that were 11.8 and $15.8 \mathrm{cM}$ from each side of the everbearing gene and constructed a linkage map of that region. These searches for markers did not require genome-wide mapping because $R p f$ and everbearing are each controlled by a single dominant gene. However, many desirable traits are complex and regulated by multiple genes; therefore, QTL mapping is essential. QTL analyses of the octoploid strawberry are severely lagging behind those of diploids. In diploid wild species, especially $F$. vesca, genomic study has steadily progressed. ISSR markers within $2.2 \mathrm{cM}$ of a seasonal flowering gene were identified (Albani et al., 2004; Cekic et al., 2001), and a high-precision genetic map based on SSR markers has been built for the interspecies derived from the cross F. vesca $\times$ F. nubicola (Sargent et al., 2004a, 2006). In polyploids, there are two main reasons for the delays in mapping progress: (1) There are a large number of possible genotypes for each DNA marker, and these genotypes cannot always be identified by their banding phenotypes; and (2) the genome constitutions (allo- or autopolyploidy) of many high-level polyploids are not clearly understood. Wu et al. (1992) suggested a general method for mapping polyploids based on single-dose (SD) markers to overcome these problems. An SD marker is defined as a DNA fragment that is present on just one chromosome in one of the parents and can be identified by $1: 1$ segregation, regardless of ploidy. The first reported genome-wide map in the cultivated strawberry consisted of AFLP markers (Lerceteau-Köhler et al., 2003). The authors combined a pseudo-testcross strategy (Grattapaglia and Sederoff, 1994) with SD marker analysis because of the high heterozygosity of $F$. $\times$ ananassa, and constructed two maps (female and male). On the basis of the strategy above, a more advanced map was reported by RousseauGueutin et al. (2008), who used SSR markers in addition to AFLPs and integrated the maps of female and male using anchor markers. The constructed linkage groups were divided into hypothesized homoeologous groups I 
to VII by comparing with maps of diploid Fragaria species. Sargent et al. (2009) also built a map of cultivated strawberry ordered by homoeologous group, mainly with SSR and AFLP markers. They suggested the locations of probable chromosomal duplications or translocations during the evolution of Fragaria by comparing the octoploid map to the map of diploid species. Spigler et al. (2008) created a genetic map of the wild octoploid $F$. virginiana with 42 linkage groups, and found that the two loci that determine sex were in the same linkage group. This result suggested the existence of a primitive sex chromosome in Fragaria. Recent advancements in mapping the octoploid strawberry will facilitate the discovery of QTLs regulating important phenotypes, such as disease resistance or fruit quality. Weebadde et al. (2008) have already reported the first QTL to be mapped in $F$. $\times$ ananassa, loci that control day-neutrality.

In 2011, whole-genome sequencing of $F$. vesca was completed and released by Shulaev et al. (2011) (http://www.strawberrygenome.org). The genome sequences were anchored to the diploid Fragaria map (Sargent et al., 2006), and aligned by the linkage group. Using this valuable information, the development of DNA markers and QTL mapping in $F$. $\times$ ananassa will progress at an increasing pace.

\section{4) Search for ancestral species}

$F$. $\times$ ananassa is directly descended from two wild octoploid species, F. virginiana and F. chiloensis, which are native to North and South America. These two octoploids were introduced into Europe in the early $1700 \mathrm{~s}$, and after a brief interval, the origin of $F \times$ ananassa was documented by Duchesne. Fragaria species include various ploidy levels from $2 x$ to $10 x$ (Table 1). The polyploid species of strawberry are considered to have arisen via interspecies crosses and chromosome doubling of diploids. The currently accepted genome composition of the octoploids is AAA'A'BBB'B'; these genomes were donated by at least two ancestral species, which had not been identified. Senanayake and Bringhurst (1967) investigated chromosome pairing of interspecies aneuploids (pentaploid and hexaploid) generated by crossing diploids ( $F$. vesca and F.viridis) with octoploids (F.virginiana and F. chiloensis), and found pairing between the genome of these diploid species and part of the genome of octoploids, indicating that these species possess related genomes (labeled as $\mathrm{A}$ or $\mathrm{A}^{\prime}$ ).

The first molecular biology tool for addressing the question of strawberry genome origin was RFLPs of chloroplast DNA (Harrison et al., 1997). The authors analyzed the relationships among nine Fragaria species at various polyploidy levels by studying 66 observed mutations. It was revealed that diploid species $F$. nilgerrensis and F. vesca were comparatively divergent, and that diploid species F. iinumae was the most
Table 1. Fragaria species of various ploidy levels.

\begin{tabular}{lcl}
\hline Species & Ploidy level & Geographic distribution \\
\hline F. iturupensis & $8 x-10 x$ & East Asia \\
F. virginiana & $8 x$ & North America \\
F. chiloensis & $8 x$ & Western North and South America \\
F. moschata & $6 x$ & Europe, Russia \\
F. orientalis & $4 x$ & Northeastern Asia \\
F. moupinensis & $4 x$ & Southwest Chine \\
F. gracilis & $4 x$ & Northwest China \\
F. viridis & $2 x$ & Europe, Asia \\
F. vesca & $2 x$ & Europe, Asia, North America \\
F. nubicola & $2 x$ & Central Asia, China \\
F. nilgerrensis & $2 x$ & Central Asia, China \\
F. pentaphylla & $2 x$ & China, Tibet \\
F. daltoniana & $2 x$ & Himalaya \\
F. mandshurica & $2 x$ & Northeastern Asia \\
F. yezoensis & $2 x$ & Japan, Russia \\
F. nipponica & $2 x$ & Japan \\
F. iinumae & $2 x$ & Japan \\
\hline
\end{tabular}

divergent and ancestral among Fragaria species. The progenitors of the octoploid species could not be determined. More detailed phylogenetic study was attempted by comparing nuclear (internal transcribed spacer) and chloroplast DNA (trnL intron and trnL-trnF spacer) sequences (Potter, 2000). Fourteen Fragaria species were classified by comparing 'representative' sequence of each species, and the conclusion was again reached that $F$. iinumae was the most ancestral among the species tested. Additionally, F. vesca and F. nubicola were judged to be most closely related to polyploids, including tetraploid $F$. orientalis, hexaploid F. moschata, and octoploids F.chiloensis, F. virginiana, and $F . \times$ ananassa. SSR markers were also used for construction of a phylogenetic tree; however, they showed inadequate resolution compared to sequence data due to unrelated alleles being identical in length (Sargent et al., 2004b). The transferability of SSR markers derived from $F$. $\times$ ananassa among Fragaria species was assessed by Davis et al. (2006), and presented as follows: F. vesca $(98.4 \%$ transferability from $F . \times$ ananassa $)>F$. iinumae $=$ F. nubicola $(93.8 \%)>$ F. mandshurica $(87.5 \%)>$ F. nilgerrensis $(75 \%)>$ F. viridis $(73.4 \%)$. Considering the studies described here, the genome donor of the octoploid genome could be $F$. vesca, with $F$. nubicola being the next most likely candidate. In those studies, however, the phylogenetic relationships had been assessed without considering the ploidy level of each Fragaria species: each species, including diploids and octoploids, was characterized by a single representative DNA sequence, or by common markers uniformly. The similarity of whole genomes could be calculated, but that of each constituent genome could not be analyzed in polyploids. For example, F. nubicola was considered to be the second closest species to the octoploids (after F. vesca); however, this information does not allow us 
to judge which genome it was closer to, A or B (A is defined as the genome related to $F$. vesca). In octoploids, which possess multiple genomes assumed to derive from different origins, it is desirable that phylogenetic studies be performed considering each of the component genomes. The genome-specific markers developed in $F$. $\times$ ananassa could distinguish genes on a specific genome from the set of homoeologous genomes due to their high selectivity; on the other hand, transferability of these markers to other species was distinctly low (around $20 \%$ ). Therefore, these markers should detect specific genomes in common between $F$. ananassa and various wild strawberry species.

Kunihisa (2008) applied 19 genome-specific primer pairs to 13 Fragaria species, and examined whether they detected the targeted genome (Table 2). Twelve primer pairs performed highly specific amplification; two of them (for $\mathrm{F} 3 \mathrm{H} 3$ and MSR locus) amplified the genes on the target genome in F. vesca (2x), F. nubicola $(2 x)$, F. moschata (6x), and all of the octoploid species. This result showed that these two primer pairs were specific to the A genome in octoploids. It was highly likely that $F$. vesca, not F. nubicola, donated the A genome to octoploids, considering the results obtained for the DFR locus. If $F$. nubicola had donated its genome to octoploid species, the amplicons from the DFR locus of these species would have been identical; however, the sizes of amplicons from these species were different. It is more reasonable to consider that $F$. vesca is the A genome donor, and that the primer pair for DFR locus amplified the loci on genomes other than A. This result is consistent with the highest transferability of SSR markers from $F$. $\times$ ananassa to F. vesca reported by Davis et al. (2006). F. nubicola was revealed to be the second closest to the A genome, not closely related to the B genome. The remaining 10 primer pairs did not detect any genomes from tested species except in octoploids. They were presumably specific to the A', B, or B' genome, because they generated no amplicon in F. vesca possessing A genome. The genome donors of $\mathrm{A}^{\prime}, \mathrm{B}$, and $\mathrm{B}^{\prime}$ might be untested or extinct species; alternatively, these genomes might have differentiated after chromosome doubling. The primer pair for the DFR loci, which was low-specific and seemed to amplify the loci on the genomes other than A, indicated that F.daltoniana, F. iinumae, or F. nilgerrensis was related to A', B, or B' genome. The results obtained in this study are incomplete because the information provided by detecting the presence of amplicons is limited compared to that obtained by sequence data; however, the effectiveness of phylogenetic comparison taking genome structure into consideration was confirmed.

Rousseau-Gueutin et al. (2009) resolved the problem of genome origin by analysis of homoeologous sequence data. They obtained all homoeologous sequences of lowcopy nuclear genes in 20 Fragaria species through massive DNA sequencing, and then classified them. Sequences were divided into clades designated $\mathrm{X}, \mathrm{Y}$, and $Z$. Some sequences from the octoploids belonged to clade $\mathrm{Y}$, which also contained the diploids F. vesca and F. mandshurica; the other sequences from octoploids belonged to clade $\mathrm{Z}$, which also contained the diploid F. iinumae. The sequences of other diploids, including F. nubicola, belonged to clade $\mathrm{X}$, which was closer to

Table 2. Result of genome-specific amplification in Fragaria species.

\begin{tabular}{|c|c|c|c|c|c|c|c|c|c|c|c|c|c|c|c|c|c|c|c|c|}
\hline \multirow{4}{*}{$\begin{array}{c}\text { Species } \\
\text { ( ): number of } \\
\text { tested strains }\end{array}$} & \multirow{4}{*}{$\begin{array}{r}\text { Ploidy } \\
\text { level }\end{array}$} & \multicolumn{19}{|c|}{ Amplified locus } \\
\hline & & \multicolumn{12}{|c|}{ High specificity } & \multicolumn{4}{|c|}{ Low specificity } & \multicolumn{3}{|c|}{ No specificity } \\
\hline & & $\stackrel{M}{\stackrel{M}{I}}$ & $\stackrel{\tilde{n}}{\Sigma}$ & $\stackrel{㐅}{\stackrel{\alpha}{\alpha}}$ & $\begin{array}{l}\text { 㐫 } \\
\text { 完 }\end{array}$ & 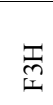 & 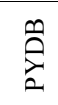 & 悹 & $\Xi$ & $\overrightarrow{0}$ & $\Xi$ & $\stackrel{\vartheta}{\Xi}$ & 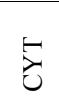 & $\frac{c}{\Delta}$ & $\underset{\widetilde{I}}{\stackrel{I}{I}}$ & $\frac{2}{2}$ & 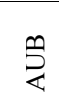 & ङ & $\frac{x}{2}$ & 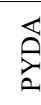 \\
\hline & & $\mathrm{S}$ & $\mathrm{S}$ & $\mathrm{S}$ & $\mathrm{S}$ & $\mathrm{S}$ & $\mathrm{S}$ & $\mathrm{S}$ & $\mathrm{S}$ & $\mathrm{S}$ & $\mathrm{S}$ & $\mathrm{S}$ & $\mathrm{S}$ & $\mathrm{M}$ & $\mathrm{M}$ & $\mathrm{S}$ & $\mathrm{S}$ & $\mathrm{M}$ & $\mathrm{M}$ & $\mathrm{S}$ \\
\hline$F . \times$ ananassa $(4)$ & ) $8 x$ & $\bigcirc$ & $\bigcirc$ & $\bigcirc$ & $\bigcirc$ & $\bigcirc$ & $\bigcirc$ & $\bigcirc$ & 0 & $\bigcirc$ & 0 & $\bigcirc$ & $\bigcirc$ & $\bigcirc$ & $\bigcirc$ & $\bigcirc$ & $\bigcirc$ & $\bigcirc$ & $\bigcirc$ & 0 \\
\hline F. virginiana (2) & $8 x$ & 0 & $\bigcirc$ & 0 & $\bigcirc$ & 0 & 0 & 0 & 0 & $\bigcirc$ & 0 & 0 & $\bigcirc$ & 0 & $\bigcirc$ & 0 & $\bigcirc$ & $\bigcirc$ & 0 & 0 \\
\hline F. chiloensis (3) & $8 x$ & $\bigcirc$ & $\bigcirc$ & $\bigcirc$ & $\bigcirc$ & 0 & $\bigcirc$ & $\bigcirc$ & 0 & $\bigcirc$ & 0 & $\bigcirc$ & $\bigcirc$ & 0 & $\bigcirc$ & $\bigcirc$ & $\bigcirc$ & $\bigcirc$ & $\bigcirc$ & 0 \\
\hline F. moschata (2) & $6 x$ & $\bigcirc$ & $\bigcirc$ & & & & & & & & & & & 0 & $\triangle$ & $\bigcirc$ & $\triangle$ & $\bigcirc$ & $\bigcirc$ & 0 \\
\hline F. orientalis (1) & $4 x$ & & & & & & & & & & & & & 0 & & $\bigcirc$ & $\triangle$ & 0 & $\bigcirc$ & 0 \\
\hline F. nipponica (3) & $2 x$ & & & & & & & & & & & & & 0 & & $\bigcirc$ & $\triangle$ & 0 & 0 & 0 \\
\hline F. pentaphylla (3) & $2 x$ & & & & & & & & & & & & & 0 & & $\bigcirc$ & $\triangle$ & 0 & $\bigcirc$ & $\bigcirc$ \\
\hline F. viridis (2) & $2 x$ & & & & & & & & & & & & & & $\triangle$ & $\triangle$ & $\triangle$ & $\bigcirc$ & $\bigcirc$ & 0 \\
\hline F. nubicola (1) & $2 x$ & $\bigcirc$ & $\bigcirc$ & & & & & & & & & & & 0 & $\triangle$ & $\triangle$ & $\triangle$ & $\bigcirc$ & $\bigcirc$ & 0 \\
\hline F. vesca (4) & $2 x$ & $\bigcirc$ & $\bigcirc$ & & & & & & & & & & & & & $\triangle$ & & $\bigcirc$ & $\bigcirc$ & 0 \\
\hline F. daltoniana (1) & $2 x$ & & & & & & & & & & & & & 0 & & & $\triangle$ & $\bigcirc$ & $\bigcirc$ & 0 \\
\hline F. iinumae (2) & $2 x$ & & & & & & & & & & & & & 0 & $\triangle$ & & $\triangle$ & $\bigcirc$ & $\bigcirc$ & $\bigcirc$ \\
\hline F. nilgerrensis (2) & $2 x$ & & & & & & & & & & & & & $\bigcirc$ & $\triangle$ & & & 0 & $\bigcirc$ & 0 \\
\hline
\end{tabular}

S, M: Single and Multi locus in $F$. $\times$ ananassa.

$\bigcirc$, amplification of an intense band of the expected size; $\triangle$, amplification of a weak band of expected size of unexpected size. 
$\mathrm{Y}$ than to $\mathrm{Z}$. The genomic constructions of other polyploid species were also indicated by this analysis. Additional study of F. iinumae, a species for which little genetic information is currently available, is expected in the future.

The identification of ancestral species would promote the resolution of important phenotypes and comparative mapping in the cultivated strawberry, as well as facilitating the production of novel combinations. For example, an artificially reduplicated interspecies hybrid between $F$. $\times$ ananassa and a wild species attracted attention as a newly created species with unique traits (Noguchi et al., 2002); however, such doubling hybrid had low fertility due to unequable pairing of chromosomes, when the crossed wild species contained a genome homologous to that of those in $F$. $\times$ ananassa (Morishita et al., 1996). The clarification of homology between genomes of various genetic resources would enable us to estimate the fertility of planned interspecies hybrids.

\section{Identification of $\boldsymbol{F} \times$ ananassa cultivars}

\section{1) Genotyping of various cultivars}

Cultivar classification of $F$. $\times$ ananassa by molecular means was first attempted with isozymes (Bringhurst et al., 1978, 1979). Gidoni et al. (1994) later reported the ability to distinguish eight $F$. $\times$ ananassa cultivars by using a set of 10 RAPDs. RAPDs were applied to identification of the patented, economically valuable variety 'Marmolada', and the results were accepted as evidence in court (Congiu et al., 2000). AFLP markers were also an effective tool for this purpose due to the higher reproducibility and detectability of polymorphisms, although the procedure for analysis was more complicated (Degani et al., 2001; Tyrka et al., 2002). ISSR markers were then introduced as a comparatively simple, reproducible, and discriminative tool (Arnau et al., 2003). The RAPD, AFLP, and ISSR markers could efficiently generate a large number of polymorphisms; however, their reproducibility is not very high due to competition among unknown numbers of targeted loci. Techniques such as a ligation step and/or polyacrylamide gel electrophoresis required high level skill, and made us hesitate to recommend these methods for use in local inspection stations. The procedures for CAPS and SSR analyses were simpler, and the detected polymorphisms were more stable because the number of loci targeted in each amplification reaction was limited (Kunihisa et al., 2003; Shimomura and Hirashima, 2006); however, competition among eight homoeologous sequences in each reaction caused the polymorphic signals to be weak or sometimes invisible. DNA identification might to be applied in court cases, so having a reliable technique is essential; therefore, genome-specific DNA markers with reproducibility as high as in diploids are adequate for polyploid strawberries. Although SSR analysis is reliable, it often requires expensive equipment for genotyping, so this method would also be difficult to implement in local stations. Then genome-specific CAPS markers were applied to 125 strawberry cultivars and could discriminate 117 cultivars (Kunihisa et al., 2005a, 2009a). The remaining eight were mutant clones and their original cultivars. The 112 genetically closest individuals within a sib-line could also be distinguished by these markers.

In 1999, the amount of strawberries imported from neighboring Asian country began to increase rapidly, going from $165 \mathrm{t}$ in 1998 to $1408 \mathrm{t}$ in 2001 (Trade Statistics of Japan; www.customs.go.jp/toukei/srch/ index.htm). There were strong suspicions that cultivars 'Sachinoka' and 'Tochiotome', which had been patented by domestic institutes, might be found among these imported strawberries. This would indicate the taking and propagation of seedlings without permission, representing an infringement of breeders' rights. In addition to strawberries, rushes (Juncus effusus L.) and cherries (Prunus avium) had similar problems. In 2002, the examination of imported strawberries was begun using CAPS markers. As a result of this examination, packed fruits labeled as 'Nyoho' were found to be a mix of 'Redpearl' and 'Sachinoka' (Kunihisa et al., 2005b). With these results in hand, NIVTS admonished dealers who handled these fruits against the business of buying and selling illegally grown strawberries. The breeder who had developed 'Redpearl' had gone to court with the aim of stopping the import of 'Redpearl' in 2001. These cases promoted public awareness of patents for agricultural crops. The volume of imported strawberry fruits from Asian countries sharply decreased to about $200 \mathrm{t}$ in 2003, and has been at that level until the present.

In 2007, RAPD and AFLP markers were converted to very simple and reproducible sequence tagged site (STS) markers for the discrimination of strawberry cultivars. The ability to use multiplex systems compensated for the low discrimination power of STS markers, which are dominant (Amagai et al., 2007). A multiplex system was also applied to SSR markers; genotyping with 10 primer pairs was performed by only three PCR reactions, and $56 \mathrm{~F}$. $\times$ ananassa cultivars could be discriminated by these markers (Govan et al., 2008). SSR markers are rapid and cost-effective when DNA genotyping equipment is available in the laboratory.

\section{2) Validation of DNA marker reproducibility across laboratories}

Reproducibility is an indispensable characteristic for widespread applicability of any analysis method. A largescale comparative study among laboratories was carried out for genotyping of grape cultivars using SSR markers (This et al., 2004). Forty-six cultivars were genotyped with six SSR primer pairs in 11 independent laboratories. The allele sizes obtained for each cultivar by different laboratories were not in satisfactory agreement; the data for identical alleles differed by as much as 5 bp between 
laboratories. Therefore, the investigators selected 33 reference cultivars that covered almost all of the alleles detected by the six markers, and the genotypes of tested samples were determined by comparison with reference alleles, not by the absolute allele size. Using this method, over $96 \%$ of alleles became identical among collaborators. The remaining discrepancies were consistent and unexplainable 1-2 bp shifts for several alleles. However, it must be noted that they did not standardize the method for DNA extraction, PCR condition, and signal detection. If all of the analysis methods had been identical in the study, the reproducibility of SSR markers might have been higher.

In the cultivated strawberry, the SSR markers selected for genotyping by Govan et al. (2008) were tested for their reproducibility in two other laboratories (Brunings et al., 2010). Although Govan et al. (2008) had used multiplex PCR, Brunings et al. (2010) examined the signals detected by each primer pair individually. The comparison of allele sizes of common cultivars detected in different laboratories revealed some discrepancies, including missing or additional signals, and 1-2 bp shifts, as shown in grapes. In octoploids, it would be more difficult to produce consistent results by SSR markers than in diploid grapes, probably due to competition of amplification among homoeologous loci. The use of primers in multiplex reactions would make it all the more difficult to obtain reproducible results.

At the time when the problem of reproducibility across laboratories began to be considered, a general validation system for DNA fingerprinting of crops had not yet been established. Kunihisa et al. (2009b) then focused on the Official Methods of Analysis (OMA) of AOAC International (AOACI). The AOACI is a worldwide facilitator of the development, use, and harmonization of validated analytical methods for foods. A validation study matching the AOACI criteria is required before a method can be listed in the OMA. The study for a qualitative test method must be designed as a blind test, and presentation of sensitivity $(100 \%$ minus falsenegative rate) and specificity (100\% minus false-positive rate) rates is required. The authors designed a collaborative study according to the AOAC criteria: a minimum of 10 laboratories, a minimum of 2 analyte levels per matrix, a minimum of 6 test samples per level, and 6 negative controls per matrix (AOAC International, 2002). The only reported qualitative methods validated according to these criteria had been to detect toxic bacteria (Feldsine et al., 1997, 2003), so Kunihisa et al.'s study was the first evaluation of the genotyping of crop cultivars by DNA markers. In the study, strawberry leaves (coded to conceal the cultivar name) were genotyped in at least 12 laboratories according to the instruction manual (http://vegetea.naro.affrc.go.jp/joho/ manual/ichigo/ichigo_manual.html), following a pre-test to confirm the technical level of each collaborator (Kunihisa et al., 2009b). The study was designed to satisfy the criteria of having a blind test with at least two genotypes per marker and six replicated samples per genotype (Fig. 4). Sensitivity and specificity rates calculated from the results reported from collaborators were over $97 \%$ for 23 out of the 25 validated markers; the remaining two markers were accurately scored at rates of $95.8 \%$ and $90.0 \%$. McClure (1990) stated that a minimally acceptable method must correctly classify at least $80 \%$ of the test samples.

The validated genome-specific CAPS markers are less discriminating than SSR markers, but they possess a high level of reproducibility quantified by an authoritative method, and they do not require any expensive equipment or extensive training. They are suitable for general use in local inspection stations, breeding facilities, and so on. Validation of the methods used for DNA genotyping of other crops is also needed for a more reliable check system.

\section{3) Cultivar identification with a probability theory}

Two kinds of probability need to be carefully

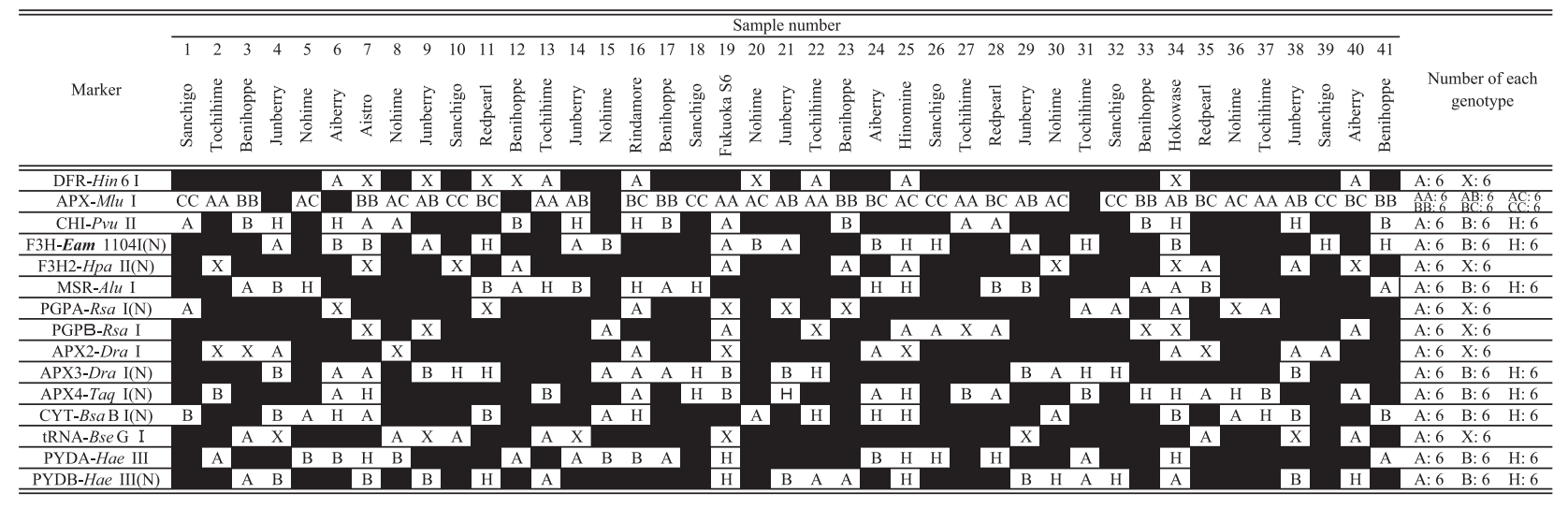

Fig. 4. Example of design for validation of genotyping of $F$. $\times$ ananassa (Kunihisa et al., 2009). The blind test was designed so that each marker genotype was present in at least six samples. Each collaborator sent the sheet back to the coordinator with the genotypes they detected marked in the empty cells. 
considered in forensic DNA identification. The first is the probability of mistyping a sample when using a particular method, which can be represented as falsenegative and false-positive rates (discussed in the previous section). The second is the probability of an unlisted (unknown) cultivar having a completely identical genotype to that of one of the listed candidates. The DNA methods for crop cultivars are, in the strict sense, not for "identification", but for "distinction of a limited number of cultivars". When there is the possibility that a sample could come from an unlisted cultivar, "identification" is possible only when the probability of accidental DNA matching is specified. To meet this requirement for identification, Ukai (2004) proposed a "theory of cultivar identification". The probability $\left(P_{1}\right)$ that at least one cultivar among a set of $n$ listed cultivars is identical to the tested sample in an analysis using $k$ markers can be calculated using the following formula:

$$
P_{1}=1-\left(1-f_{1} \cdot f_{2} \cdot f_{3} \cdots f_{k}\right)^{n}
$$

(The frequency of a genotype detected by marker $i$ is $f_{i}$ $\left[0<f_{i}<1\right]$.)

This theory was applied to the CAPS-marker-based genotyping technique to improve the technique's utility (Kunihisa et al., 2009a). Statistical independence of DNA markers is desirable because it allows genotype frequencies to be multiplied across loci to obtain a multilocus genotype probability (Risch et al., 1992). The independence of every possible pair of CAPS markers was checked by the chi-square test, and 16 independent markers were selected. The frequency of each genotype detected by these markers was calculated from genotype data of 125 cultivars described in the previous section. In conclusion, the 16 selected markers can identify all listed strawberry cultivars except mutant derivatives with a probability of $>99.9 \%$. However, the frequency of genotypes could change as new cultivars are added to the list, so it would need to be recalculated in the future for accurate probability.

\section{Conclusion}

Genomic studies supporting effective and novel breeding in the cultivated strawberry have lagged behind those of other crops despite its economic importance and enthusiastic breeding programs, primarily because of its complex polyploidy. However, recent progress in DNA marker techniques for strawberries is leading to the conclusion that $F$. ananassa is mainly amphidiploid, with the genomic formula AAA'A'BBB'B'. The release of higher-quality genetic maps and QTL analyses for important traits under complex genetic control are expected, as the technology continues to progress.

The CAPS genome-specific markers introduced in this review are not well suited for use in the development of maps or markers linked to traits, because a great deal of labor is required to obtain them. However, they could serve as "key markers" which are useful in particular genetic studies. These markers would enable us to examine the genetic behavior of each genome independently and to obtain information that could not be obtained from the usual markers, which have to be treated as dominant. CAPS markers are most suitable for DNA fingerprinting, which is required to be simple, highly reproducible, and easy to transfer; however, it is inefficient in development of markers. For general genomic studies, genome-specific markers should be developed by the SSR method, which provides a reasonable balance of efficient development and reproducibility. Homoeologous genome-specific markers are particularly informative and their development should be encouraged. SSR marker signals generated by the same primer pair are highly polymorphic and assumed to be homoeologous (Rousseau-Gueutin et al., 2008); therefore, resolution of general SSR markers into a maximum of four disomic markers should not be very difficult. Markers for homoeologous loci would be useful not only as anchor markers for the integration of maps, but to divide homoeologous linkage groups into $\mathrm{A}, \mathrm{A}^{\prime}$, $\mathrm{B}$, and $\mathrm{B}^{\prime}$ genome groups. In past studies, linkage groups have been distributed among homoeologous groups 17 without difficulty by comparing them with maps of ancestral diploids, or in cases when markers generated from the same primer pairs were regarded as homoeologous. The identification of $\mathrm{A}, \mathrm{A}^{\prime}, \mathrm{B}$, or $\mathrm{B}^{\prime}$ genome groups has been the most challenging problem. The A group (A and $\mathrm{A}^{\prime}$ ) and $\mathrm{B}$ group (B and $\left.\mathrm{B}^{\prime}\right)$ might be distinguishable through comparative mapping; however, in the end, the affinity of mapped markers (or sequences around them) to $F$. vesca (or F. iinumae) would be a measure for discrimination between $\mathrm{A}$ and $\mathrm{A}^{\prime}$ (or $\mathrm{B}$ and $\left.\mathrm{B}^{\prime}\right)$. To that end, comparable homoeologous markers should be located on the map. A complete map of the cultivated strawberry that identifies all of the chromosomes from $1 \mathrm{~A}$ to $7 \mathrm{~B}^{\prime}$, similar to those currently available for wheat, would be a very valuable achievement.

For hexaploid wheat, all of the genomes were identified long ago, and interspecies hybridization or manipulation of ploidy has been carried out based on solid theory. Significant manpower, materials, and funding have been supplied for wheat. The cultivated strawberry is lagging far behind wheat, especially in genomic study. However, the quality of genome maps available for strawberry is steadily improving, so the identification and detection of each genome should be achieved in the near future. These achievements would support the whole-genome sequencing of $F$. $\times$ ananassa, which might possess many confusing gene copies.

In Japan, some laboratories with high technical capabilities are able to combine various types of markers for strawberry cultivar identification. However, many laboratories, such as customs offices, national institute for genetic resources, private food research centers, more 
than 10 prefectural agriculture centers, and training programs in colleges use CAPS markers, which are easy to use and highly reproducible. The CAPS technique satisfies two important criteria for DNA identification required in forensic cases: the validity of the analytical technique, and the presentation of probability of accidental matching of DNA type. The example of CAPS markers is presented as one model for DNA identification of crops.

\section{Literature Cited}

Albani, M. C., N. H. Battey and M. J. Wilkinson. 2004. The development of ISSR-derived SCAR markers around the seasonal flowering locus (SFL) in Fragaria vesca. Theor. Appl. Genet. 109: 571-579.

Amagai, M., K. Tasaki and Y. Kashiwaya. 2007. The method for identification of strawberry (Fragaria $\times$ ananassa Duchesne) cultivars detecting polymorphic DNA sequences by multiplex PCR. Japan Patent 2007-252318.

AOAC International. 2002. Guidelines for collaborative study procedures to validate characteristics of a method of analyses. http://www.aoac.org/vmeth/omamanual/omamanual.htm.

Arnau, G., J. Lallemand and M. Bourgoin. 2003. Fast and reliable strawberry cultivar identification using inter simple sequence repeat (ISSR) amplification. Euphytica 129: 69-79.

Arulsekar, S., R. S. Bringhurst and V. Voth. 1981. Inheritance of PGI and LAP isozymes in octoploid cultivated strawberries. J. Amer. Soc. Hort. Sci. 106: 679-683.

Ashley, M. V., J. A. Wilk, S. M. N. Styan, K. J. Craft, K. L. Jones, K. A. Feldheim, K. S. Lewers and T. L. Ashman. 2003. High variability and disomic segregation of microsatellites in the octoploid Fragaria virginiana Mill. (Rosaceae). Theor. Appl. Genet. 107: 1201-1207.

Bassil, N. V., M. Gunn, K. Folta and K. Lewers. 2006. Microsatellite markers for Fragaria from 'Strawberry Festival' expressed sequence tags. Mol. Ecol. Notes 6: 473476.

Bringhurst, R. S. 1990. Cytogenetics and evolution in american Fragaria. HortScience 25: 879-881.

Bringhurst, R. S., S. Arulseker and V. Voth. 1979. Electrophoretic characterization of California strawberry cultivars. HortScience 14: 439 (Abstr.).

Bringhurst, R. S., J. F. Hancock, S. Arulseker and V. Voth. 1978. Characterizing strawberry cultivars by isozyme analysis and some applications. HortScience 13: 358 (Abstr.).

Brunings, A. M., C. Moyer, N. Peres and K. M. Folta. 2010. Implementation of simple sequence repeat markers to genotype Florida strawberry varieties. Euphytica 173: 63-75.

Byrne, D. and G. Jelenkovic. 1976. Cytological diploidization in the cultivated octoploid strawberry Fragaria $\times$ ananassa. Can. J. Genet. Cytol. 18: 653-659.

Cekic, C., N. H. Battey and M. J. Wilkinson. 2001. The potential of ISSR-PCR primer-pair combinations for genetic linkage analysis using the seasonal flowering locus in Fragaria as a model. Theor. Appl. Genet. 103: 540-546.

Congiu, L., M. Chicca, R. Cella, R. Rossi and G. Bernacchia. 2000. The use of random amplified polymorphic DNA (RAPD) markers to identify strawberry varieties: a forensic application. Mol. Ecol. 9: 229-232.

Da Silva, J. A. G. and B. W. S. Sobral. 1996. Genetics of polyploids. p. 3-38. In: B. W. S. Sobral (ed.). The Impact of Plant Molecular Genetics. Birkhäuser, Boston.

Da Silva, J. A. G., M. E. Sorrells, W. L. Burnquist and S. D.
Tanksley. 1993. RFLP linkage map and genome analysis of Saccharum spontaneum. Genome 36: 782-791.

Davis, T. M., L. M. DiMeglio, R. Yang, S. M. N. Styan and K. S. Lewers. 2006. Assessment of SSR marker transfer from the cultivated strawberry to diploid strawberry species: functionality, linkage group assignment and use in diversity analysis. J. Amer. Soc. Hort. Sci. 131: 506-512.

Degani, C., L. J. Rowland, A. Levi, J. A. Hortynski and G. J. Galletta. 1998. DNA fingerprinting of strawberry (Fragaria $\times$ ananassa) cultivars using randomly amplified polymorphic DNA (RAPD) markers. Euphytica 102: 247-253.

Degani, C., L. J. Rowland, J. A. Saunders, S. C. Hokanson, E. L. Ogden, A. Golan-Goldhirsh and G. J. Galletta. 2001. A comparison of genetic relationship measures in strawberry (Fragaria $\times$ ananassa Duch.) based on AFLPs, RAPDs, and pedigree data. Euphytica 117: 1-12.

Federova, N. 1946. Crossability and phylogenetic relations in the main European species of Fragaria. Comp. Rend. Acad. Sci. USSR 53: 545-547.

Feldsine, P. T., A. H. Lienau, R. L. Forgey and R. D. Calhoon. 1997. Visual immunoprecipitate assay (VIP) for Listeria monocytogenes and related Listeria species detection in selected foods: collaborative study. J. AOAC Int. 80: 791805.

Feldsine, P. T., A. H. Lienau, S. C. Leung, L. A. Mui, F. Humbert, M. Bohnert, K. Mooijman, S. Schulten, P. I. Veld, P. Rollier, R. Leuschner and K. Capps. 2003. Detection of Salmonella in fresh cheese, poultry products, and dried egg products by the ISO 6579 Salmonella culture procedure and the AOAC official method: collaborative study. J. AOAC Int. 86: 275295.

Gidoni, D., M. Rom, T. Kunik, M. Zur, E. Izsak, S. Izhar and N. Firon. 1994. Strawberry cultivar identification using random amplified polymorphic DNA (RAPD) markers. Plant Breed. 113: 339-342.

Govan, C. L., D. W. Simpson, A. W. Johnson, K. R. Tobutt and D. J. Sargent. 2008. A reliable multiplexed microsatellite set for genotyping Fragaria and its use in a survey of $60 \mathrm{~F}$. $\times$ ananassa cultivars. Mol. Breeding 22: 649-661.

Grattapaglia, D. and R. Sederoff. 1994. Genetic linkage maps of Eucalyptus grandis and Eucalyptus urophylla using a pseudotestcross: mapping strategy and RAPD markers. Genetics 137: 1121-1137.

Halldén, C., M. Hansen, N. O. Nilsson, A. Hjerdin and T. Säll 1996. Competition as a source of errors in RAPD analysis. Theor. Appl. Genet. 93: 1185-1192.

Harrison, R. E., J. J. Luby and G. R. Furnier. 1997. Chloroplast DNA restriction fragment variation among strawberry (Fragaria spp.) taxa. J. Amer. Soc. Hort. Sci. 122: 63-68.

Haymes, K. M., B. Henken, T. M. Davis and W. E. Weg. 1997. Identification of RAPD markers linked to a Phytophthora fragariae resistance gene (Rpfl) in the cultivated strawberry. Theor. Appl. Genet. 94: 1097-1101.

Ibrahim, A. M. F., K. Sadanaga and E. L. Denisen. 1981 Chromosomal behavior in octoploid strawberry progenies and their parental clones during meiosis. J. Amer. Soc. Hort. Sci. 106: 522-526.

Ichijima, K. 1926. Cytological and genetic studies on Fragaria. Genetics 11: 590-604.

Kunihisa, M. 2008. Development of genome-specific DNA markers in $F \times$ ananassa and their application to cultivar identification (In Japanese with English summary). Ph.D. Thesis, University of Tsukuba, Tsukuba.

Kunihisa, M., N. Fukino and S. Matsumoto. 2005a. CAPS markers improved by cluster-specific amplification for identification 
of octoploid strawberry (Fragaria $\times$ ananassa Duch.) cultivars, and their disomic inheritance. Theor. Appl. Genet. 110: $1410-1418$.

Kunihisa, M., S. Matsumoto and N. Fukino. 2003. Development of cleavage amplified polymorphic sequence (CAPS) markers for identification of strawberry cultivars. Euphytica 134: 209215.

Kunihisa, M., S. Matsumoto and N. Fukino. 2005b. Cultivar identification of strawberry fruits imported from Korea by use of DNA markers. Bull. Natl. Inst. Veg. Tea Sci. 4: 7176 (In Japanese with English abstract).

Kunihisa, M., H. Ueda, N. Fukino and S. Matsumoto. 2009a. DNA markers for identification of strawberry (Fragaria $\times$ ananassa Duch.) cultivars based on probability theory. J. Japan. Soc. Hort. Sci. 78: 211-217.

Kunihisa, M., H. Ueda, N. Fukino and S. Matsumoto. 2009b. Genotyping of strawberry (Fragaria $\times$ ananassa Duch.) cultivars by DNA markers: Interlaboratory study. J. AOAC Int. 92: 896-906.

Lerceteau-Köhler, E., G. Guérin, F. Laigret and B. DenoyesRothan. 2003. Characterization of mixed disomic and polysomic inheritance in the octoploid strawberry (Fragaria $\times$ ananassa) using AFLP mapping. Theor. Appl. Genet. 107: $619-628$

Lewers, K. S., S. M. N. Styan and S. C. Hokanson. 2005. Strawberry GenBank-derived and genomic simple sequence repeat (SSR) markers and their utility with strawberry, blackberry, and red and black raspberry. J. Amer. Soc. Hort. Sci. 130: 102-115.

Longley, A. E. 1926. Chromosomes and their significance in strawberry classification. J. Agr. Res. 15: 559-568.

MacKey, J. 1970. Significance of mating systems for chromosomes and gametes in polyploids. Hereditas 66: 165-176.

MacKey, J. 1987. Implications of polyploidy breeding. Biol. Zent. Bl. 106: 257-266.

Martinez-Zapater, J. M. and J. L. Oliver. 1984. Genetic analysis of isozyme loci in tetraploid potatoes (Solanum tuberosum L.). Genetics 108: 669-679.

McClure, F. D. 1990. Design and analysis of qualitative collaborative studies: minimum collaborative program. J. AOAC Int. 73: 953-960.

Mok, D. W. S. and W. D. Evans. 1971. Chromosome associations at diakinesis in the cultivated strawberry. Can. J. Genet. Cytol. 13: 231-236.

Monma, S., S. Okitsu and K. Takada. 1990. Inheritance of everbearing in cultivated strawberry. Bull. Natl. Res. Inst. Veg. Ornam. Plants Tea Jpn. Ser. C1: 21-29 (In Japanese with English abstract).

Morishita, M., O. Yamakawa and T. Mochizuki. 1996. Studies on interspecific hybrids of strawberry. Bull. Natl. Res. Inst. Veg. Ornam. Plants Tea Jpn. Ser. A11: 69-95 (In Japanese with English abstract).

Noguchi, Y., T. Mochizuki and K. Sone. 2002. Breeding of a new aromatic strawberry by interspecific hybridization, Fragaria $\times$ ananassa $\times$ F. nilgerrensis. J. Japan. Soc. Hort. Sci. 71: 208213.

Potter, D. 2000. Phylogenetic relationships among species of Fragaria (Rosaceae) inferred from non-coding nuclear and chloroplast DNA sequences. Systematic Botany 25: 337-348.

Powers, L. 1944. Meiotic studies of crosses between Fragaria ovalis and $F$. $\times$ ananassa. J. Agr. Res. 69: 435-448.

Risch, N. J. and B. Devlin. 1992. On the probability of matching DNA fingerprints. Science 255: 717-720.

Rousseau-Gueutin, M., A. Gaston, A. Aïnouche, M. L. Aïnouche, K. Olbricht, G. Staudt, L. Richard and B. Denoyes-Rothan.
2009. Tracking the evolutionary history of polyploidy in Fragaria L. (strawberry): New insights from phylogenetic analyses of low-copy nuclear genes. Mol. Phylogen. Evol. 51: 515-530.

Rousseau-Gueutin, M., E. Lerceteau-Köhler, L. Barrot, D. J. Sargent, A. Monfort, D. Simpson, P. Arus, G. Guérin and B. Denoyes-Rothan. 2008. Comparative genetic mapping between octoploid and diploid Fragaria species reveals a high level of colinearity between their genomes and the essentially disomic behavior of the cultivated octoploid strawberry. Genetics 179: 2045-2060.

Sargent, D. J., J. Clarke, D. W. Simpson, K. R. Tobutt, P. Arus, A. Monfort, S. Vilanova, B. Denoyes-Rothan, M. Rousseau, K. M. Folta, N. V. Bassil and N. H. Battey. 2006. An enhanced microsatellite map of diploid Fragaria. Theor. Appl. Genet. 112: 1349-1359.

Sargent, D. J., T. M. Davis, K. R. Tobutt, M. J. Wilkinson, N. H. Battey and D. W. Simpson. 2004a. A genetic linkage map of microsatellite, gene-specific and morphological markers in diploid Fragaria. Theor. Appl. Genet. 109: 1385-1391.

Sargent, D. J., F. Fernandéz-Fernandéz, J. J. Ruiz-Roja, B. G. Sutherland, A. Passey, A. B. Whitehouse and D. W. Simpson. 2009. A genetic linkage map of the cultivated strawberry (Fragaria $\times$ ananassa) and its comparison to the diploid Fragaria reference map. Mol. Breeding 24: 293-303.

Sargent, D. J., A. M. Hadnou, M. J. Wilkinson, N. H. Battey and J. A. Hawkins. 2004b. Cross-species amplification and phylogenetic reconstruction using Fragaria microsatellite primers. Acta Hort. 649: 87-92.

Senanayake, Y. D. A. and R. S. Bringhurst. 1967. Origin of Fragaria polyploids. I. Cytological analysis. Am. J. Bot. 54: 221-228.

Shimomura, K. and K. Hirashima. 2006. Development and characterization of simple sequence repeats (SSR) as markers to identify strawberry cultivars (Fragaria $\times$ ananassa Duch.). J. Japan. Soc. Hort. Sci. 75: 399-402.

Shulaev, V., D. J. Sargent, R. N. Crowhurst, T. C. Mockler, O. Folkerts, A. L. Delcher, P. Jaiswal, K. Mockaitis, A. Liston, S. P. Mane, P. Burns, T. M. Davis, J. P. Slovin, N. Bassil, R. P. Hellens, C. Evans, T. Harkins, C. Kodira, B. Desany, O. R. Crasta, R. V. Jensen, A. C. Allan, T. P. Michael, J. C. Setubal, J. M. Celton, D. J. Rees, K. P. Williams, S. H. Holt, J. J. Ruiz Rojas, M. Chatterjee, B. Liu, H. Silva, L. Meisel, A. Adato, S. A. Filichkin, M. Troggio, R. Viola, T. L. Ashman, H. Wang, P. Dharmawardhana, J. Elser, R. Raja, H. D. Priest, D. W. Jr. Bryant, S. E. Fox, S. A. Givan, L. J. Wilhelm, S. Naithani, A. Christoffels, D. Y. Salama, J. Carter, E. Lopez Girona, A. Zdepski, W. Wang, R. A. Kerstetter, W. Schwab, S. S. Korban, J. Davik, A. Monfort, B. Denoyes-Rothan, P. Arus, R. Mittler, B. Flinn, A. Aharoni, J. L. Bennetzen, S. L. Salzberg, A. W. Dickerman, R. Velasco, M. Borodovsky, R. E. Veilleux and K. M. Folta. 2011. The genome of woodland strawberry (Fragaria vesca). Nat. Genet. 43: 109116.

Spigler, R. B., K. S. Lewers, D. S. Malin and T-L. Ashman. 2008. Genetic mapping of sex determination in a wild strawberry, Fragaria virginiana, reveals earliest form of sex chromosome. Heredity 101: 507-517.

Stebbins, G. L. 1971. Chromosomal evolution in higher plants. Edward Arnold Ltd., London.

Sugimoto, T., K. Tamaki, J. Matsumoto, Y. Yamamoto, K. Shiwaku and K. Watanabe. 2005. Detection of RAPD markers linked to the everbearing gene in Japanese cultivated strawberry. Plant Breed. 124: 498-501.

This, P., A. Jung, P. Boccacci, J. Borrego, R. Botta, L. Costantini, 
M. Crespan, G. S. Dangl, C. Eisenheld, F. Ferreira-Monteiro, S. Grando, J. Ibàňez, T. Lacombe, V. Laucou, R. Magalhães, C. P. Meredith, N. Milani, E. Peterlunger, F. Regner, L. Zulini and E. Maul. 2004. Development of a standard set of microsatellite reference alleles for identification of grape cultivars. Theor. Appl. Genet. 109: 1448-1458.

Truong, C., A. E. Palme, F. Felber and Y. Naciri-Graven. 2005. Isolation and characterization of microsatellite markers in the tetraploid birch, Betula pubescens ssp. tortuosa. Mol. Ecol. Notes 5: 96-98.

Tyrka, M., P. Dziadczyk and J. A. Hortyňski. 2002. Simplified AFLP procedure as a tool for identification of strawberry cultivars and advanced breeding lines. Euphytica 125: $273-$ 280.

Ukai, Y. 2004. Theory of cultivar identification. Agric. Hortic. (Nogyo-oyobi-engei) 79: 194-198 (In Japanese).
Wall, A. M., R. Riley and M. D. Gale. 1971. Position of a locus on chromosome 5B of Triticum-Aestivum affecting homoeologous meiotic pairing. Genet. Res. 18: 329-339.

Weebadde, C. K., D. Wang, C. E. Finn, K. S. Lewers, J. J. Luby, J. Bushakra, T. M. Sjulin and J. F. Hancock. 2008. Using a linkage mapping approach to identify QTL for day-neutrality in the octoploid strawberry. Plant Breed. 127: 94-101.

Wu, K. K., W. Burnquist, M. E. Sorrells, T. L. Tew, P. H. Moore and S. D. Tanksley. 1992. The detection and estimation of linkage in polyploids using single-dose restriction fragments. Theor. Appl. Genet. 83: 294-300.

Yanagi, T., K. E. Hummer, T. Iwata, K. Sone, P. Nathewet and T. Takamura. 2010. Aneuploid strawberry $(2 n=8 x+2=58)$ was developed from homozygous unreduced gamete $(8 x)$ produced by second division restitution in pollen. Sci. Hortic. 125: $123-128$. 